
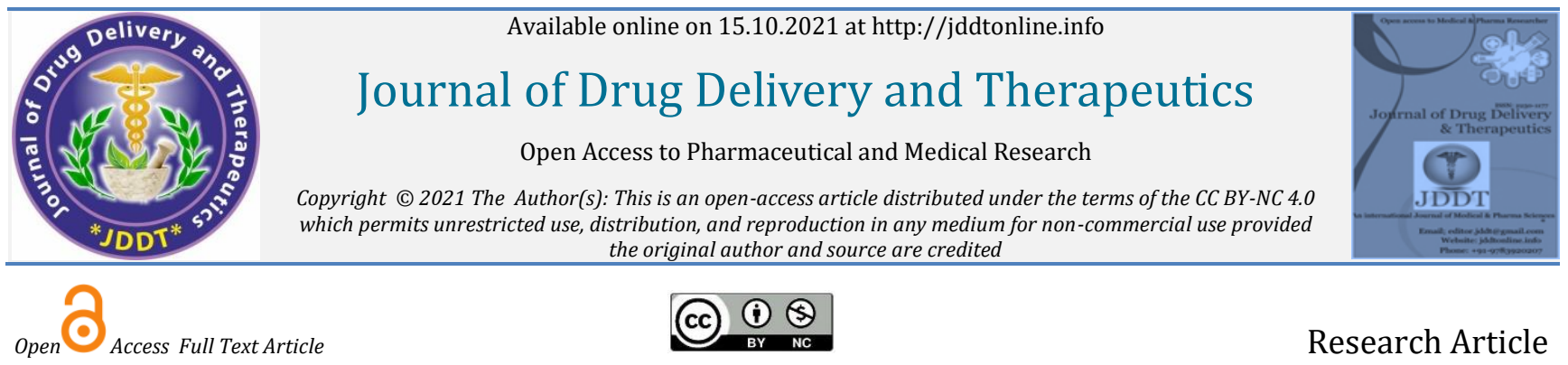

Research Article

\title{
Biochemical and resistance profile of Helicobacter pylori isolated in N’Djamena in Chad
}

Nadlaou Bessimbaye ${ }^{* 1,3,4}$, Ali Mahamat Moussa ${ }^{2,3}$, Mayanna Habkréo ${ }^{2}$, Ali Senoussi Moukhtar ${ }^{4}$, Choua Ouchemi ${ }^{3}$

1 Laboratory Service of the National Reference University Hospital (CHU-RN) of N'Djamena (Chad).

2 Department of Gastroenterology of the National Reference University Hospital (CHU-RN) of N'Djamena (Chad).

3 Faculty of Human Health Sciences, University of N'Djamena (Chad).

4 Bacteriology Unit of the Research, Diagnostic and Scientific Expertise Laboratory (Labo-ReDES) of the Faculty of Human Health Sciences. (FSSH).

Article Info:

\begin{tabular}{ll}
\hline$\square$ & Article History: \\
& Received 19 August 2021 \\
& Accepted 03 October 2021 \\
& Published 15 October 2021
\end{tabular}

\section{Cite this article as:}

Bessimbaye N, Moussa AM, Habkréo M, Moukhtar AS, Ouchemi C, Biochemical and resistance profile of Helicobacter pylori isolated in N'Djamena in Chad, Journal of Drug Delivery and Therapeutics. 2021; 11(5-S):33-41

DOI: http://dx.doi.org/10.22270/jddt.v11i5-S.5013

*Address for Correspondence:

Nadlaou Bessimbaye

$\checkmark$ Lecturer-Researcher, Faculty of Human Health Sciences (FSSH), University of N'Djamena, BP 1117 N'Djamena, Chad

$\checkmark$ Biologist, Head of the Research and Training Unit (URF) and Head of Department, Laboratories of the National Reference University Hospital (CHU-RN) of N'Djamena.

\section{Abstract}

Helicobacter pylori infection and resistance to antibiotics is a public health problem. The objective of this study was to determine the prevalence and rates of resistance to antibiotics used in the protocol for the management of patients with Helicobacter pylori infection.

Spanning a period from February 2020 to February 2021, it was an observational diagnostic study on gastric biopsies and stool including 97 patients admitted for endoscopy. It was carried out according to standard methods of medical microbiology.

Of 97 patients whose mean age was 46.10 years with extremes of 16 and 85 years, an infection prevalence of $60.82 \%$ was observed. $44.07 \%$ of infected patients were between 16 and 39 years old, $33.90 \%$ between 40 and 63 years old, and $22.03 \%$ between 63 and 85 years old.

Significant differences were observed between the proportions of positive $(81.44 \%)$ and negative $(18.56 \%)$ cultures, between infection with $H$. pylori $(75 \%)$ and other microbial agents $(25.35 \%)$ with probabilities of 0.01 and 0.02 respectively.

The most resistant antibiotics were: Metronidazole, Clarithromycin, Levofloxacin, Tetracycline and Amoxicillin with resistance rates of $74.58 \%, 16.95 \%, 13.56 \%, 8.47 \%$, and $5.08 \%$ respectively. The frequencies of antibiotic resistance revealed $74.58 \%$ for Metronidazole, $16.95 \%$ for Clarithromycin, $13.56 \%$ for Levofloxacin, $8.47 \%$ for Tetracycline, and $5.08 \%$ for Amoxicillin.

This study made it possible to determine a significant proportion of $H$. pylori infection and to shed light on the resistance to the antibiotics used in the eradicating treatment of the bacteria. From this study, we retain that the prescription of Metronidazole is prohibited in Chad.

Keywords: Helicobacter pylori, Resistance, Antibiotic, Chad.

\section{INTRODUCTION}

Helicobacter pylori is a helical, micro-aerophilic Gramnegative bacterium whose main reservoir is the human stomach 1. Present in 20 to $30 \%$ of the population of industrialized countries, and in 70 to $90 \%$ of the inhabitants of developing countries, it was the most widespread bacterial infection in the world with a prevalence of $50 \%$ of the world population in $2016^{2-5}$. It is the main agent responsible for chronic gastritis and peptic ulcers, and is also involved in the onset of stomach cancer (class 1 carcinogen according to the WHO in 1994) in 1 to $3 \%$ of infected cases (adenocarcinoma and MALT lymphoma) 6, 7.

Discovered in 1875 by German researchers, it was then highlighted and characterized for the first time in 1982 by two Australian researchers (Nobel Prize for Medicine in 2005: J. Robin Warren and Barry J. Marshall) ${ }^{1}$. Thirty years later, medicine is faced with the problem of $\mathrm{H}$. pylori's resistance to antibiotics. This resistance is mainly to clarithromycin, a very effective macrolide when administered in combination, but also to imidazoles, fluoroquinolones and to a lesser extent other antibiotic $\mathbf{8 , 9}$.

In fact, the objective of achieving eradication in all patients treated with the first therapeutic approach, a situation usual for common infectious diseases, has not been achieved for $\mathrm{H}$. pylori. The initial sensitivity of $H$. pylori to both clarithromycin and imidazoles, essential drugs for first-line triple therapy, was gradually reduced. Likewise, the low rate of resistance of $\mathrm{H}$. pylori to the fluoroquinolones primarily used for second-line therapy observed in the past has 
increased over the past decade, while rates of resistance to against amoxicillin and tetracycline seem to have remained weak 10.

Antibiotic resistance has a crucial role in the management of H. pylori infection, it is the main cause of treatment failure. Therefore, knowing resistance can help develop new management strategies to improve treatment success, it can also help prevent resistance.

In Chad, data on the resistance of $H$. pylori to antibiotics is not yet available, but infection was frequent with a prevalence of $83.7 \%$ in dyspeptic patients undergoing upper gastrointestinal endoscopy at the Internal Medicine Service. and Gastroenterology of the General National Reference Hospital of N'Djamena in 2010. Hence the need to study resistance, which is the main cause of therapeutic failure $\mathbf{1 1}$

The general objective of the present study is to contribute to improving the management of patients with Helicobacter pylori infection. To achieve this objective, we have set ourselves the following specific objectives:

$\checkmark$ Determine the prevalence of Helicobacter pylori infection in symptomatic patients admitted to the HGE Department of the CHU-RN;

$\checkmark$ Identify the strains of $\mathrm{H}$. pylori and determine their resistance to the antibiotics used in the PEC protocol.

\section{MATERIAL AND METHODS}

\section{Study framework}

This work was carried out at the Hepato-Gastroenterology (HGE) department, at the Biomedical Analysis Laboratory of the National Reference University Hospital (CHURN) of N'Djamena, and at the Research, Diagnosis and Scientific Expertise Laboratory. (Labo-ReDES) of the Faculty of Human Health Sciences (FSSH).

\section{Type and period of study}

This was a prospective, observational, descriptive and analytical diagnostic study that lasted 12 months from February 2020 to February 2021.

\section{Study population}

Were included in this study all patients of all sex and age admitted to the Hepato-Gastroenterology department of the CHU-RN, presenting symptoms suggestive of an infection with H. pylori.

\section{Inclusion criteria}

$\checkmark$ Indication and performance of digestive endoscopy;

$\checkmark$ Verbal consent of the patient or his beneficiary.

\section{Non-inclusion criteria}

$\checkmark$ The impossibility, contraindication or non-performance of digestive endoscopy or gastric biopsy samples;

$\checkmark$ The patient's refusal (or his successor in title) to participate in the study;

In the event of treatment in progress or in the four weeks preceding endoscopy, with Proton Pump Inhibitors (PPIs), Non-Steroidal Anti-Inflammatory Drugs (NSAIDs) or antibiotics.

\section{Sampling}

Sampling for convenience in relation to the duration of the study.

\section{Study variables}

$\checkmark$ The status of patients on H. pylori infection;

$\checkmark$ Gender, age, profession, origin of patients, notion of selfmedication with antibiotics, reason for consultation, result of endoscopy;

$\checkmark$ The sensitivities and resistance of the different strains to the different antibiotics mentioned.

\section{Biopsy and stool collection}

The gastric biopsy was done during the endoscopy performed by the hepato-gastroenterologist, and it was in the precondition of fasting at least 8 hours. All procedures were explained to patients or their beneficiaries. They were free to consent or refuse. Two biopsies (antral and fundal) were taken from each patient using gastrointestinal endoscopic biopsy forceps. The transport between the Hepato-Gastro-Enterology Service (SHGE) and the laboratories was done immediately after the sample. The biopsies were transported in $5 \mathrm{~mL}$ tubes containing $1.5 \mathrm{~mL}$ of saline. The whole was transported in a Cool box to the CHURN laboratory for analysis.

The stools were collected by the patients in sterile vials.

\section{CULTURE}

We used four types of culture media in this study. These were pylori agar supplied to us by BioMérieux, chocolate agar (GC), Columbia blood agar (GCS) and Mueller Hinton blood agar ((GMHS) that we prepared in the laboratory. For these two Last, we used the base agars (Columbia agar and Mueller Hinton agar), presented as lyophilized powder and fresh sheep blood as. Mueller Hinton blood agar was used for the antibiogram, the other three for the culture. of Helicobacter pylori.

We then added $10 \mathrm{~mL}$ of mixture of VCN (Vancomycin, Colistin, Nystatin) antibiotics and selective antifungals in the culture media to inhibit the growth of molds and unwanted bacteria.

\section{Preparation and inoculation of samples}

In the laboratory, in order to avoid contamination, most of the handling was carried out under a microbiological safety hood. Each biopsy was dilacerated with a scalpel in a petri dish to be inoculated in three media (G. pylori, GCS, and GC), one part used for Gram stain, and a last part for the urea test. The stools were also inoculated in different culture media.

From the dilaceration product, we deposited a suspension in the center of each culture medium (G. pylori, GCS, and GC) and we spread by several framing using the loop so that the entire half-surface of the box is seeded without touching the edges of the box (Photo: Table). Each culture medium was incubated at $37^{\circ} \mathrm{C}$ under a micro-aerobic atmosphere (Photo: Table). The culture was checked every 3 days from the 1st day until 12 days. A positive $H$. pylori culture was explained by the appearance of small round, domed and transparent colonies (Photos 9 and 10). It was confirmed by microscopic observation after Gram stain where $H$. pylori appear pink in spiral form, and by biochemical tests (catalase + , oxidase + and urease +++ ). A negative culture was confirmed 12 days after incubation when the criteria described for a positive culture were absent.

\section{Detection of urease activity}

Part of the debris from the biopsy or stool was suspended in $100 \mu \mathrm{L}$ of urea medium and placed at $37^{\circ} \mathrm{C}$ for 24 hours. In 
the presence of the bacteria, a colorimetric change from red from phenol to pink is observed.

\section{GRAM staining}

On a part of the product of laceration of the biopsy or of the stool, we had carried out a direct examination after staining of GRAM. For this, we deposited part of the said product on a slide and then spread in such a way as to obtain a smear, which, after drying, we carried out the GRAM staining.

On microscopic observation, at the objective $\mathrm{x} 100$, we understand the morphology and the color of bacteria. Colonies of H. pylori appear curved, spiraling, and pink.

Study of the sensitivity of $\mathrm{H}$. pylori isolated from diarrhea and biopsies to antibiotics

The antibiogram was carried out manually by the Kirby and Bauer method, which is the method by diffusing discs impregnated with antibiotics in agar medium, and measuring the diameter of inhibition (Photos: Table). In our study, the antibiotics we were interested in were in Table 1.

\section{Inoculation procedure}

Within 15 minutes of adjusting the turbidity of the inoculum suspension, a cotton swab was dipped into the suspension. The soaked swab was squeezed firmly by twisting it against the bottom wall of the tube just above the liquid level to remove excess inoculum. Then it was spread three (3) times over the entire surface of the agar, rotating the dish approximately $60^{\circ}$, after each application, to obtain an even distribution of the inoculum. Finally, all over the edge of the agar surface was swabbed.

\section{Procedure for dispensing antibiotic-impregnated discs}

$6.35 \mathrm{~mm}$ diameter blotting paper discs impregnated with a determined load of antibiotic were used for the antibiogram tests. 5-10 min after the inoculum, the antibiotic discs were applied to the Petri dishes. We place the discs individually with sterile forceps or using a dispenser against the agar. The number of discs per Petri dish must be such that the zones of inhibition do not intersect in order to allow reading of the diameters in several directions. The number of discs chosen varies between 6 to 7 per box of $90 \mathrm{~mm}$. Once the discs have been placed on the agar, they are left at laboratory temperature $\left(25^{\circ} \mathrm{C}\right)$ for about 30 minutes and then we bring them to incubation for 24 hours at $37^{\circ} \mathrm{C}$. After overnight incubation, we measure the diameter of each zone of inhibition (including disc diameter) in $\mathrm{mm}$ using a graduated measuring instrument called a caliper.

\section{Choice of antibiotics required for susceptibility testing of isolated $H$. pylori}

The data applied for the reading comes from recognized methods of the Committee of Antibiogram of the French Society of Microbiology and of the National Committee on Clinical Laboratory Standards (CA-SFM, 2016-2020; NCCLS, 1998). Table 1 below gives us the list of antibiotics, their charges and the limits of the diameters.

Table 1: Interpretation guide for antibiotic inhibition diameters (CA-SFM 2016-2020; NCCLS, 1998).

\begin{tabular}{|l|l|l|l|c|}
\hline Antibiotics & $\begin{array}{l}\text { Concentrations } \\
\text { (mm) }\end{array}$ & $\begin{array}{l}\text { Resistant } \\
\text { (mm) }\end{array}$ & $\begin{array}{l}\text { Intermediate } \\
\text { (mm) }\end{array}$ & $\begin{array}{l}\text { Sensible } \\
\text { (mm) }\end{array}$ \\
\hline Clarithromycin (CLA) & $2 \mu \mathrm{g}$ & $\emptyset<19$ & $19-20$ & $\emptyset \geq 20$ \\
\hline Amoxicillin (AML) & $20 \mu \mathrm{g}$ & $\emptyset<19$ & $19-23$ & $\emptyset \geq 23$ \\
\hline Amoxicillin + Clavulanic acid (AMC) & $20 / 10 \mu \mathrm{g}$ & $\emptyset<19$ & $19-22$ & $\emptyset \geq 22$ \\
\hline Lévofloxacin 5 $\boldsymbol{\mu g}(\mathrm{LEV})$ & $5 \mu \mathrm{g}$ & $\emptyset<19$ & $19-21$ & $\emptyset \geq 22$ \\
\hline Tetracycline (TET) & $30 \mathrm{UI}$ & $\emptyset<17$ & $17-19$ & $\emptyset \geq 19$ \\
\hline Metronidazole (MET) & $5 \mu \mathrm{g}$ & $\emptyset<11$ & $11-13$ & $\emptyset \geq 13$ \\
\hline
\end{tabular}

\section{Data processing}

The collected data was entered and analyzed using Word 2013 and Excel 2013 software. Statistical analysis used the chi-square $\left(\chi^{2}\right)$ test to compare two qualitative variables. The p-value $\leq 0.05$ was considered significant.

\section{RESULTS}

\section{Overall prevalence of infection}

A total of 97 patients were included in this study. These were 56 men $(57.73 \%)$ and 41 women $(42.27 \%)$ with a sex ratio of 1.4 an average age of 39.6 years with extremes of 16 and 85 years. After the culture on the biopsies, it resulted that out of the 97 patients sampled, 59 or $60.82 \%$ were positive for H. pylori, and 38 patients or $39.18 \%$ were negative.

\section{Distribution of infection by gender}

The distribution of infection by gender showed that the frequencies of positive cases by sex compared to the total of positive cases. We deduce that among the 59 positive cases, $57.63 \%(\mathrm{n}=34)$ were men and $42.37 \%(\mathrm{n}=25)$ women with a sex ratio of 1.36 . Processing of these data provided us with a chi-square of 0.0095 below the significant critical threshold (3.84) of $5 \%$. This allowed us to state that with a margin of error of 0.05 , the occurrence of $H$. pylori infection is not related to sex.

\section{Distribution of infection by age group}

The figure below illustrates the distribution of the 59 infected patients by age group. The most represented age group was 16 to 39 years old with 26 cases or $44.07 \%$. Processing of these data allowed us to determine a chisquare of 0.752 which was below the critical value (5.99) at the significant threshold of $5 \%$. So, we could say that with a margin of error of 0.05 , the occurrence of $H$. pylori infection is not related to age. The median age was 46.10 years with extremes of 16 and 85 years. 


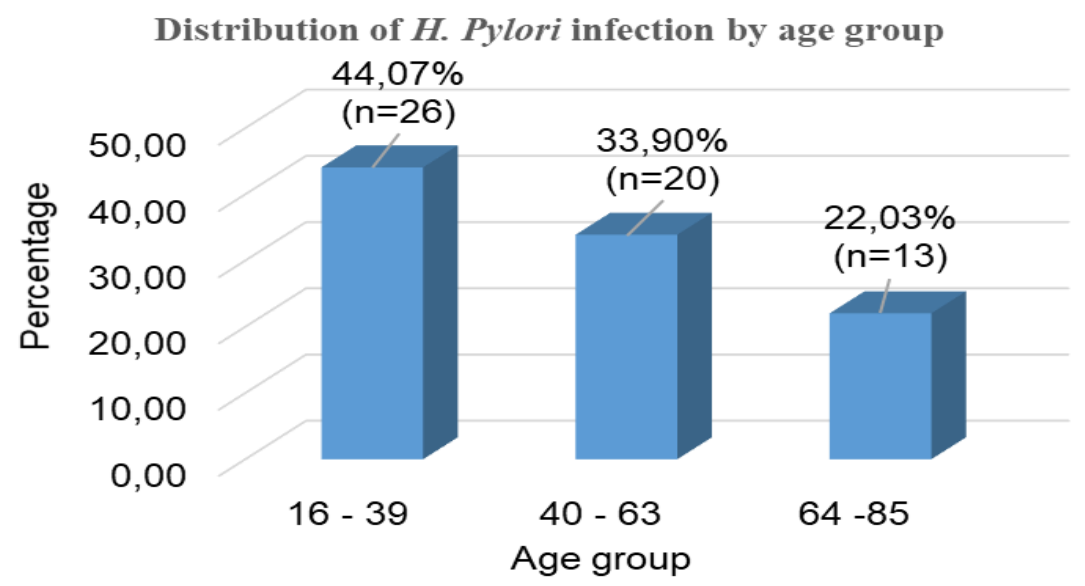

Figure 1: Distribution of H. Pylori infection by age group

\section{Breakdown of infected patients by category}

This figure illustrates the distribution of infected patients by category. Hospitalized patients represented $64.41 \%$ with a number of 38 patients. In fact, the patients undergoing endoscopy at the CHU-RN were mostly hospitalized people.

Distribution of infected patients according to category

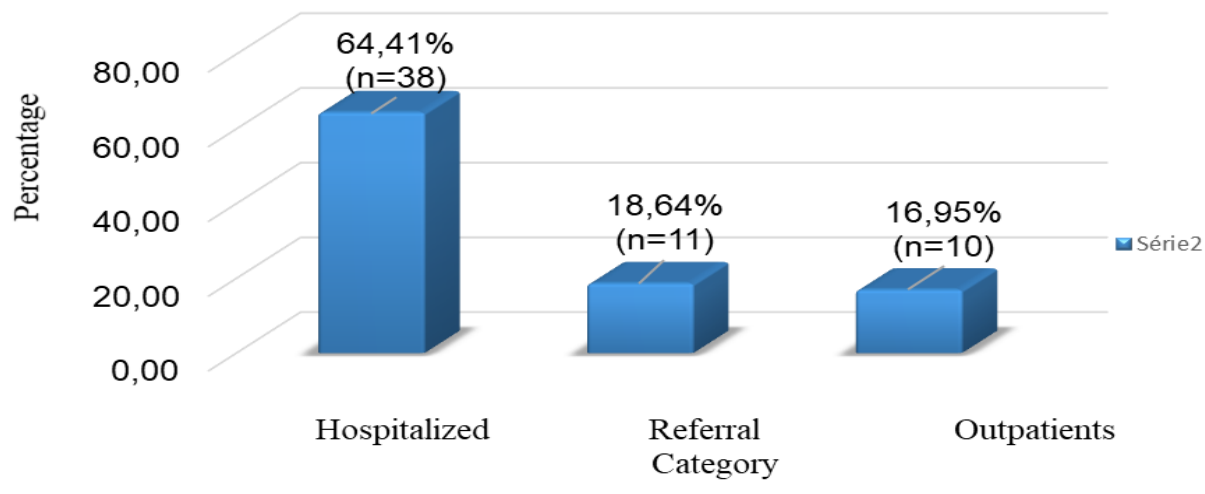

Figure 2: Distribution of positive cases by category

Distribution of infected patients by self-medication with antibiotics

Among the 59 infected patients, 33 or $55.93 \%$ said that they do not use antibiotics without a medical prescription, 14 or
$23.73 \%$ said they were in the habit of using antibiotics, and 12 or $20,34 \%$ had ignored.

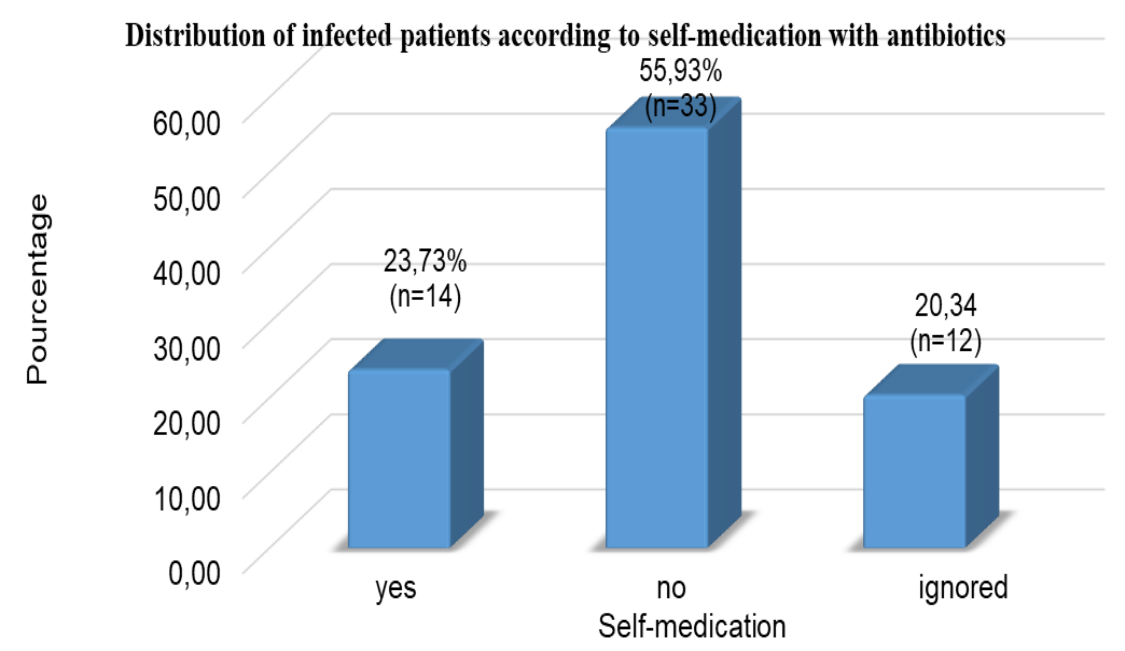

Figure 3: Distribution of positive cases according to self-medication 


\section{Breakdown of infected patients by reason for consultation}

This table shows the distribution of positive patients according to the reason for consultation. In this study, it was found that 32 patients or $54.24 \%$ had consulted for epigastralgia.

Table 2: Distribution of infected patients according to the reason for consultation

\begin{tabular}{|l|l|l|}
\hline Indication & $\mathrm{n}$ & $\%$ \\
\hline Epigastralgia & $\mathbf{3 2}$ & \\
\hline Pyrosis & 9 & 15,25 \\
\hline Dyspepsia & 4 & 6,78 \\
\hline Others* & 14 & 23,73 \\
\hline Total & $\mathbf{5 9}$ & $\mathbf{1 0 0}$ \\
\hline
\end{tabular}

$\mathrm{n}=$ number; $\%$ = percentage; $*$ (Nausea, vomiting, hematemesis, regurgitation)

Distribution of positive cases according to the endoscopy result

Of the 59 people infected, endoscopy revealed that $8.47 \%$ had normal mucosa. Among the lesions suggestive of $H$. pylori infection, we recorded $88.14 \%$ of gastritis, and high rates of gastric and duodenal ulcers with frequencies of $57.63 \%$ and $45.76 \%$ respectively, then $10.17 \%$ pseudonodular gastropathy.

The results are shown in the table below.

Table 3: Distribution of infected patients according to the endoscopy result.

\begin{tabular}{|l|l|l|}
\hline Gastroscopy result & $\mathrm{n}$ & $\%$ \\
\hline Gastritis & $\mathbf{5 2}$ & $\mathbf{8 8 , 1 4}$ \\
\hline Peptic esophagitis & 49 & 83,05 \\
\hline Gastric ulcer & 34 & 57,63 \\
\hline Duodenal ulcer & 27 & 45,76 \\
\hline Varicose veins & 7 & 11,86 \\
\hline Pseudonodular gastropathy & 6 & 10,17 \\
\hline Normal mucosa & 5 & 8,47 \\
\hline
\end{tabular}

$\mathrm{n}=$ number, $\%$ = percentage

Prevalence of bacteria isolated in different culture media

After culturing each biopsy in 3 different media, we obtained the result shown in Table 4 below. Pseudomonas, Streptococci, Staphylococci, Escherichia coli and yeast were found to grow in regular chocolate agar and disrupt the culture of $H$. pylori. Yeasts also grew in pylori agar, and only grew in vancomycin-colistin-nystatin (VCN) blood agar as $H$. pylori. We could therefore conclude that VCN would have inhibited the growth of other microbial agents for the benefit of $H$. pylori. Blood agar would be the most suitable medium for the culture of $H$. pylori.

Of the 97 cultures performed, we obtained an overall Helicobacter pylori infection rate of 59/79 (60.82\%), 79 (81.44\%) were positive and $18(18.56 \%)$ were negative $\left(\mathrm{x}^{2}\right.$ $=7.035>\mathrm{x}^{2}{ }_{0}>3.84, p=0.01$, dof $=1$, significant difference in favor of positive cultures).

Of the 79 positive cultures, 59 (75\%) of Helicobacter pylori isolated and $20(25.35 \%)$ of other isolated microbial agents $\left(\mathrm{x}^{2}=4.291>\mathrm{x}^{2} 0>3.84, p=0.02\right.$, dof $=1$, significant difference in favor of Helicobacter pylori compared to other microbial agents).

Table 4: Overall result of culture

\begin{tabular}{|l|l|l|}
\hline Microbial agents & $\mathrm{n}$ & $\%$ \\
\hline Helicobacter. pylori & 59 & 75 \\
\hline Streptococcus spp & 7 & 9 \\
\hline Streptotoccus agalactiae & 4 & 5,06 \\
\hline Candida albicans & 4 & 5,06 \\
\hline Pseudomonas aeruginosa & 2 & 2,53 \\
\hline Escherichia coli & 2 & 2,53 \\
\hline Staphylococcus aureus & 1 & 1,26 \\
\hline Total & $\mathbf{7 9}$ & $\mathbf{1 0 0}$ \\
\hline
\end{tabular}

$\mathrm{n}=$ number, $\%=$ percentage

\section{Biochemical identification of $\mathrm{H}$. pylori by urease activity}

Part of the biopsy or fecal debris was suspended in $100 \mu \mathrm{L}$ of urea medium and placed at $37^{\circ} \mathrm{C}$ for 24 hours. In the presence of the bacteria, a colorimetric change from red from phenol to pink is observed (Figure).

\section{Morphological identification of $H$. pylori by GRAM staining}

After the different steps of the GRAM staining, microscopic observation, at the objective $\mathrm{x} 100$ with oil immersion, showed us the morphology of the curved, spiral and pink $\mathrm{H}$. pylori colonies (Photo h, Table 5).

Study of the sensitivity of $H$. pylori isolated from diarrhea and biopsies to antibiotics

Six antibiotics were tested on the 59 strains of $\mathrm{H}$. pylori isolated. These were clarithromycin, levofloxacin, tetracycline, amoxicillin, amoxicillin + clavulanic acid, and metronidazole. We observed strong resistance to metronidazole. The following table indicates the frequencies of the sensitivities and resistance of the strains to antibiotics.

Table 5: Summary of antibiotics tested on isolated strains

\begin{tabular}{|l|r|r|r|r|r|r|}
\hline Antibiotiques & $\mathrm{n}$ & \multicolumn{1}{|c|}{$\%$} & $\mathrm{ni}$ & \% & $\mathrm{nr}$ & \%r \\
\hline Metronidazole & $\mathbf{9}$ & $\mathbf{1 5 , 2 5}$ & $\mathbf{6}$ & $\mathbf{1 0 , 1 7}$ & $\mathbf{4 4}$ & $\mathbf{7 4 , 5 8}$ \\
\hline Clarithromycin & 47 & $\mathbf{7 9 , 6 6}$ & 2 & 3,39 & 10 & 8,95 \\
\hline Lévofloxacin & 42 & 71,19 & 9 & 15,25 & 13,56 \\
\hline Tétracycline & 50 & 84,75 & 4 & 6,78 & 5 & 3,47 \\
\hline Amoxicillin & 56 & 94,92 & 0 & 0 & 5,08 \\
\hline Amoxicillin + CA & 56 & 94,92 & 0 & 0 & 3 & 5,08 \\
\hline
\end{tabular}

n: Number of sensitive germs, \%: Frequency of sensitive germs, ni: Number of intermediate germs, \% i: Frequency of intermediate germs, nr:

Number of resistant germs. \% r: Frequency of resistant germs. 
Table 6: Macroscopic and microscopic characteristics of Helicobacter pylori colonies

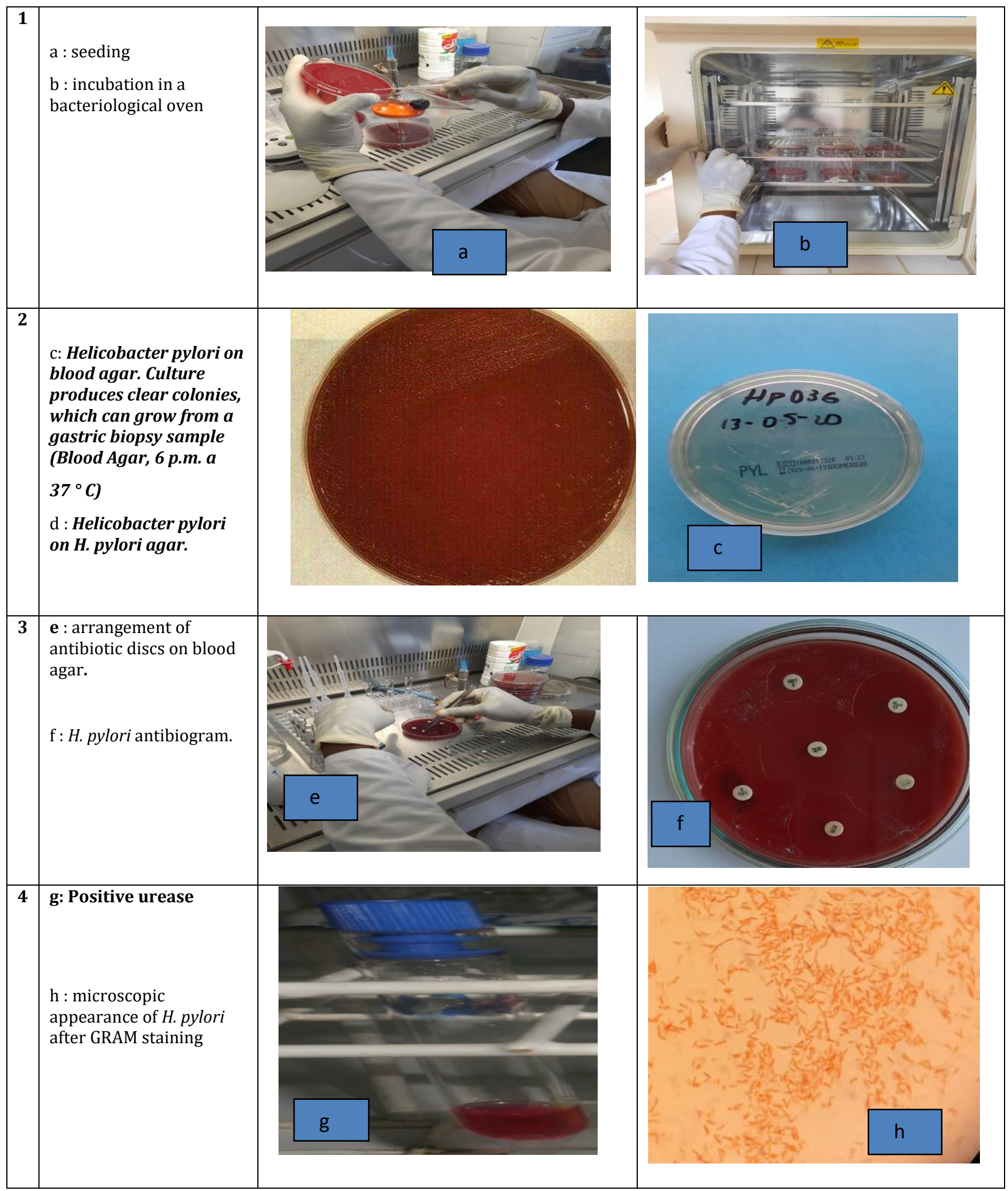

\section{DISCUSSION}

Conducted at the National Reference University of N'Djamena, the present study, the first in Chad, consisted in determining the prevalence of $H$. pylori infection as well as the resistance of the bacteria to the antibiotics used in the treatment protocol for the infection.
In this study, we determined a prevalence of $H$. pylori infection of $60.82 \%$. This prevalence was lower than that of Moussa et al, who obtained $83.7 \%$ in a study conducted at the General National Reference Hospital of N'Djamena in 2010 11. We could explain this gap by the irrational use of antibiotics due to the persistent scale of illicit markets during the last decade in the city of N'Djamena. This prevalence was also higher than that of Naîma which obtained $29 \%$ in 
Algeria in 2018 17. It was similar to that of Doffou et al in Yopougon in Côte d'Ivoire in 2002 18, to that of Dia et al, in Dakar in Senegal in 2010 16, to that of Tajeldin et al in Sudan in 201220 who reported prevalence of $57.8 \%, 65.8 \%$ and $65.8 \%$ respectively. However, it was lower than that of Firmin et al., In Yaoundé in Cameroon in 2013 21, that of Bouihat in Morocco in 2017 22, that of Ahmad in Kano in Nigeria in 2018 23, and in that of Traoré in Mali in 2020 24, which reported $72.5 \%, 69.5 \%, 81.7 \%$, and $79.60 \%$ respectively. It was higher than the prevalence observed in France, fluctuating between 15 and $30 \%$ in 2019 25. These differences in prevalence could be explained not only by the differences in living standards which are strongly linked to the onset of infection, but also to the misuse of antibiotics and the diagnostic methods used. A $60.82 \%$ prevalence of $H$. pylori infection can be explained by the low standard of living of Chadians in the developing world.

In terms of gender, it was observed $60.71 \%(34 / 56)$ in the group of men, and $60.98 \%$ (25/41) in the group of women. This result corroborates that of Moussa et al, who reported that gender did not influence the status of patients with $H$. pylori infection 11. These data were comparable to those of Joutei et al, who obtained $53 \%$ for women, $47 \%$ for men in Morocco in $2007{ }^{26}$, and to those of Bouihat who obtained $65.21 \%$ in the group of men. and $72.8 \%$ in the group of women in Morocco in 2017 22. Firmin et al, obtained 78.6\% in the group of men and $68.3 \%$ in the group of women in Yaoundé, Cameroon in 2013 21. Amel et al, had reported a prevalence of $73.2 \%$ in men, and $65.5 \%$ in women in Morocco in 2013 27. In all of these cases, the chi-square test for independence had rejected the hypothesis that the infection was gender-related. This could be explained by the acquisition of the infection which took place mainly in childhood and whose only factors favoring the onset are the immaturity of the gastric mucosa, the low socioeconomic level: hygiene, gastrointestinal enteritis, and promiscuity.

According to the age groups, and in relation to the total infected population, it was observed that the infected patients of the 16 to 39 years old group represented $44.07 \%$ (26/59), those of 40 to 63 years old represented $33.90 \%$ (20/59), and those aged 64 to 85 accounted for $22.03 \%$ $(13 / 59)$. In relation to their class size, infected patients in the 16 to 39 class represented $65 \%(26 / 40)$, those 40 to 63 years old represented $61 \%(20 / 33)$, and those aged 64 at age 85 had represented $54.17 \%$ (20/33).

This result was similar to that of Firmin et al., Who reported $83.1 \%, 67.4 \%$ and $60.8 \%$ in the groups under 40,40 to 50 , and over 50 respectively. ${ }^{21}$. It was also similar to that of Doffou et al, who had found a frequency of $57.7 \%$ in the age group of 21 to 40 years 18 , and that of Traoré who had obtained $48.74 \%$ in the age group. 15 to 40 years of age $\mathbf{2 4}$. Moussa et al, reported that age did not influence $H$. pylori infection status $\mathbf{1 1}$.

In our study, there was not a significant difference between the prevalences of the first two classes. However, the prevalence of the 64 to 85 age group was slightly lower than that of the first two classes. This could be explained by the progression of the disease with age, the intensification of lesions and symptoms, and therefore some elderly people were previously treated.

Regarding the occupation, the frequencies were between 20 and $25 \%$ for all categories. This could be explained by the almost identical standard of living or community habits among all patients despite being from different professions. On the other hand, it could be a social rise for many subjects, as they experienced precarious living conditions in infancy, when the infection occurred. Except students and retirees whose participation in the study was not significant, accounted for $8.47 \%$ and $3.39 \%$ respectively. This could be explained by the youth of the population, the resort of the population to hospitals often at a very advanced stage of the disease, and the low life expectancy.

Regarding the source, the patients were classified into 3 categories. These were hospital patients, referrals, and outpatient (outpatient) follow-ups. Hospitalized patients dominated with a frequency of $64.41 \%$, followed by patients referred from the various structures of the city which occupied a frequency of $18.64 \%$, and those who are followed externally represented $16.95 \%$. These differences could be explained by the use of the population in hospital often at a very advanced stage of the disease and therefore they occur when their condition requires hospitalization. Most of the hospitalized patients first went through the emergency department of the CHU-RN.

Self-medication, especially with antibiotics, has a crucial role in the progression of the disease, the development of resistance and the reliability of the microbiological result. During the interview, $23.73 \%$ admitted that they were used to self-medication, $55.93 \%$ said they were not used to selfmedication, and $20.34 \%$ had ignored. Doffou et al., Had reported $17.3 \%, 9.6 \%$ and $12.6 \%$ having taken a gastrotoxic drug, an antibiotic or a gastric antisecretory respectively the 4 weeks preceding the endoscopic examination in Yopougon in Côte d'Ivoire in 200218.

Speaking of the reason for the endoscopy, and compared to the infected population, patients who consulted for epigastralgia dominated with a frequency of $54.24 \%$, followed by Others (Nausea, vomiting, hematemesis, regurgitation, etc.) with $23.73 \%$, heartburn at $15.25 \%$, and dyspepsia at $6.78 \%$. These data were comparable to those of Ontsira who reported $64.3 \%$ for epigastralgia, $6.3 \%$ for dyspepsia, and $5.6 \%$ for heartburn in Congo Brazzaville in 2016 19, 28. They were similar to those of Doffou et al., Who had shown epigastralgia as the main reason for endoscopic examination with a frequency of $82.7 \%$ in Yopougon in Côte d'Ivoire in 200218.

According to the endoscopy result, the study found gastritis 88.14\%, esophagitis (more often peptic) 83.05\%, gastric ulcer $57.63 \%$, ulcer duodenal at $45.76 \%$, varicose veins at $11.86 \%$, the appearance of normal mucosa at $8.47 \%$, and pseudo-nodular gastropathy at $10.17 \%$. These data were not comparable to those of Moussa at al., Those of Ontsira, those of Firmin et al., That of Emal et al., And that of Naïma. Moussa et al., Reported $7.6 \%$ esophagitis, $2.3 \%$ gastric ulcer, and $19.8 \%$ duodenal ulcer in N'Djamena in 2010 11. Ontsira had obtained $36.4 \%$ of normal mucosa, $22.4 \%$ of gastropathy, and $17.4 \%$ of peptic ulcer disease in Congo Brazzaville in 2016 28. Firmin et al., Found that the main lesions among patients were antral gastritis at $49.7 \%$, diffuse gastritis at $29.8 \%$, duodenal ulcer at $15.8 \%$, peptic esophagitis at 11 , $1 \%$, gastric cancer at $1.2 \%$, and the examination was normal at $7.6 \%$ in Yaoundé, Cameroon in 2013 21. Emal et al., Reported $91.8 \%$ of chronic gastritis in infected patients, $5 \%$ of gastric ulcer and $3.2 \%$ of gastric cancer in Morocco in 2013 27. Naïma had reported in patients who had not undergone previous treatment, $81.6 \%$ of gastritis, followed by duodenal ulcers at $10.45 \%$, and gastric ulcers at $3.26 \%$, lymphomas at $0.65 \%$. while $3.92 \%$ of them had a normal gastric mucosa in Algeria in 2018 17. However, they remained comparable to those of Dia et al., Who had shown chronic gastritis at $60.6 \%$, duodenal ulcer at $77 \%$ and gastric ulcer at 75\% in Dakar, Senegal in 201016. 
The course of these cascades of lesions depends on the duration of the infection, and the presence of other contributing or triggering factors such as taking NSAIDs for ulcers. In this study, we did not record any cases of cancer. The high prevalence of gastric and duodenal ulcers could be explained by patients going to hospital at very advanced stages of the infection.

As we mentioned, the yeasts had grown in GC and G. Pylori. Pseudomonas, Streptococci, Staphylococci and Escherichia coli have grown in GC.

We could explain the presence of germs other than $H$. pylori by a supply of these germs in the stomach from the oral cavity and the duodenum, and by contamination during the passage of the endoscopic probe. We used the three environments in order to reassure ourselves of their reliability and to have a good result.

Regarding antibiotic resistance, that to clarithromycin is characterized by the decrease in the affinity of the antibiotic for its target and confers on the bacteria cross resistance to macrolides. We detected a sensitivity rate of $79.66 \%$ and a resistance rate of $16.95 \%$. This frequency was not comparable to those of other series reported such as $0 \%$ by Secka et al, in The Gambia in $2013^{2}, 0 \%$ by Oyedeji et al., In Nigeria in 2009 3, 0\% by Asrat et al., In Ethiopia in 2004 , $1 \%$ by Seck et al., In Senegal in $2013 \mathbf{2 8}, 1.7 \%$ by Ontsira in Congo Brazzaville in $2016{ }^{28}, 6.4 \%$ by Kimang in Kenya in $2010^{29}$. However, was similar to that of Ben Mansour et al., Who reported $15.4 \%$ in Tunisia in 2010 15, to that of Tanih et al., Who obtained $20 \%$ in South Africa in 2013 30. It was much lower than that of Raymond et al., Who found $26 \%$ in France in 2010 31, that of Bouihat who reported 28.6\% in Morocco in 2017 22, and that of Djennane- Hadibi et al., Who obtained 33\% in Algeria in 2016 32. In 2010, primary resistance to clarithromycin was $17.2 \%$ worldwide. It would be related to its prescription in respiratory infections when an atypical germ is suspected $\mathbf{1 6}$

Clavulanic acid helps overcome resistance due to betalactamase. With Amoxicillin + AC, we achieved the same result as with amoxicillin. This allowed us to confirm the absence of beta-lactamase in $H$. pylori. We determined a susceptibility rate of $94.92 \%$ and a resistance rate of $5.08 \%$ to amoxicillin. This resistance rate was different from those of Bouihat in Morocco in 2017 22, Dia et al. in Dakar in 2008 19, and Naïma in 2018 in Algeria ${ }^{17}$, who had not obtained resistance to amoxicillin. The $\mathrm{CNRCH}$ reported in its 2019 activity report a resistance of $2 \%$ in France 33 .

Amoxicillin resistance is rare, and given its low frequency, CASFM does not recommend its testing ${ }^{17}$. The frequency of resistance to amoxicillin observed in our study is among the strongest resistance of $H$. pylori to this antibiotic in the world. This could be explained by the irrational overuse of this antibiotic. Unlike clarithromycin, Levofloxacin and tetracycline, amoxicillin remains the most accessible antibiotic known and used in the Chadian community.

Levofloxacin resistance is believed to be linked to the occurrence of point mutations in a particular region of the gyr A subunit of the target DNA gyrase of fluoroquinolones. We determined a sensitivity rate of $71.19 \%$ and a resistance rate of $13.56 \%$ to levofloxacin. This resistance rate was superimposed on that of Bouihat and Kalach, but higher than that of Naïma and Ontsira. Bouihat had obtained a resistance rate of $10.7 \%$ to levofloxacin in Morocco in 2017 22, Kalach had found 13.2\% in France in 2007 14, Ontsira had obtained $1.2 \%$ in Congo Brazzaville in $2016 \mathbf{2 8}$, and Naïma reported $2 \%$ in Algeria in 2018 17. The CNRCH had reported in its annual activity report for 2019 a resistance rate of $19.1 \%$ for ISSN: 2250-1177
Levofloxacin in France 33. Globally, De Francesco et al. Reported in 2010 a frequency of $16.2 \%$ resistance to fluoroquinolones in $\mathrm{H}$. pylori, 16. These high rates of resistance could be explained by the use of levofloxacin in communities because of its prescription for urogenital and ENT infections.

The efflux is believed to be implicated in the occurrence of resistance in $H$. pylori to tetracycline, but mutations are also responsible for this resistance. We determined a susceptibility rate of $84.75 \%$ and a resistance rate of $8.47 \%$ to tetracycline. In 2010, De Francesco et al., Found a frequency of $5.9 \%$ in the world with a great disparity between Africa where it reached $43.9 \%$ 16. Ontsira et al., Had reported a resistance of $4.2 \%{ }^{28}$. The $\mathrm{CNRCH}$ in France in 2019, Naïma in 2018 in Algeria, and Bouihat in 2017 in Morocco did not find resistance to tetracycline.

Resistance to metronidazole affects several genes. It was on average 3 times higher than for macrolides worldwide in 20149 . In this study, we determined a sensitivity rate of $15.25 \%$ and a resistance rate of $74.58 \%$. This resistance rate was higher than that of Bouihat in Morocco in 2017 who had reported $40.1 \%$, and that of Ben Mansour et al, who had obtained 56\% in Tunisia in 2010 15. It was lower than that of Seck et al, who found 85\% in 2013 in Senegal 13. In Europe, it was $34.9 \%$ in adults and $25.7 \%$ in children in $2007 \mathbf{1 4}$.

This strong resistance can be explained not only by the strong prescription of this antiparasitic antibiotic in many parasitosis, whether as a preventive or curative measure, but also by the irrational use of this drug which is known to all.

\section{CONCLUSION}

Although localized, this study determined a high prevalence of $H$. pylori infection in the city of N'Djamena. This constitutes a real public health problem for Chad. The occurrence of infection does not depend on gender or age, let alone socioeconomic status. With regard to antibiotic resistance, these results suggest the need for the implementation of management procedures guided by the results of the antibiogram.

Finally, we recommend that large-scale studies be carried out in the provinces in order to better understand the extent of the resistance of $H$. pylori to the various antibiotics used for its eradication.

Acknowledgments: The authors thank the patients who participated voluntarily and by informed consent in this study. Our thanks also go to the Dean of the Faculty of Human Health Sciences of the University of N'Djamena and to the Director General of CHURN N'Djamena for granting permission to conduct this study.

Conflict of Interest: The authors declare that they have no conflict of interest.

Ethical and Administrative Considerations: Our study previously received:

- Authorization from the Dean of the Faculty of Human Health Sciences (FSSH), University of N'Djamena (Chad);

- Authorization from the Director General of the National Reference General University Hospital (CHIRN) of N'Djamena (Chad);

- Verbal consent of each patient or his beneficiary to whom we have explained the procedure and the importance of the study and their participation. 


\section{REFERENCES}

1. Marshall B, Warren R, "Unidentified curved bacilli in the stomach of patients with gastritis and peptic ulceration" Lancet, 1984; 1(8390): 1311-15. https://doi.org/10.1016/S01406736(84)91816-6

2. Secka O, Berg DE, Antonio M, Corrah T, Tapgun M, Walton R, Vivat T, Galano JJ, Sancho J, Adegbola RA et Thomas JE, "Antimicrobial susceptibility and resistance patterns among Helicobacter pylori strains from The Gambia, West Africa" Antimicrobial Agents Chem, 2013; 57(3):1231-7.

https://doi.org/10.1128/AAC.00517-12

3. Correa P, Puazuelo MB, "Natural history of Helicobacter pylori infection" Dig Foie Dis, 2008;40(7):490-506. https://doi.org/10.1016/j.dld.2008.02.035

4. Eun CS, Kim BK, Han DS, Kim SY, Kim KM, CHoi BY, Sang CK, Kim YS et Kim JF, "Differences in gastric mucosal microbiota profiling in patients with chronic gastritis, intestinal metaplasia and gastric cancer using pyrosequencing methods" Helicobacter, 2014; 19(6):407-416. https://doi.org/10.1111/hel.12145

5. Backert S, Clyne M "Pathogenesis of Helicobacter pylori infection. Helicobacter" PMID: 21896081, 2011; Suppl 1:19-25. https://doi.org/10.1111/j.1523-5378.2011.00876.x

6. Mégraud F , Coenen S , Versporten A, Kist A , Lopez-Bréa M , Hirschl AM , Andersen LP, Goossens H, Glupczynski Y Helicobacter pylori resistance to antibiotics in Europe and its relationship to antibiotic consumption, 2013; 62(1):34-42. https://doi.org/10.1136/gutjnl-2012-302254

7. Zhang R-G, Duan G-C, Fan Q-T, Chen S-Y, "Pathogenesis of Helicobacter pylori infection. Helicobacter" World J Gastrointest Pathophysiol, 2016; 15; 7(1):97-107. Help Desk: http://www.wjgnet.com/esps/helpdesk.aspx https://doi.org/10.4291/wjgp. v7.i1.97

8. Megraud F, Coenen S, Versporten A, Kist M, Lopez-Bréa M , Hirschl AM, Andersen LP, Goossens H, Glupczynski Y, "Helicobacter pylori resistance to antibiotics in Europe and its relationship to antibiotic consumption" Gut, 2013; 62(1):34-42. https://doi.org/10.1136/gutjnl-2012-302254

9. De Korwin JD, "Helicobacter pylori 30 years after: What's new?" Rev Med Interne, 2014; 35(9):561-574. https://www.fmcgastro.org https://doi.org/10.1016/j.revmed.2014.01.009

10. Megraud F, Lehours P "Helicobacter pylori detection and antimicrobial susceptibility testing" Clin Microbiol Rev, 2007; 20 (2):280-322. https://doi.org/10.1128/CMR.00033-06

11. Moussa AM, Mayanna H, Choua O, Bessimbaye N, Mahamat Saleh T, Tidjani $\mathrm{A}$ « Les manifestations cliniques et endoscopiques de l'infection à Helicobacter pylori à N'Djamena' Annales de l'Université de N'Djamena » Série C. 2018; 10 :109-127

12. Krajden S, Fuksa M, Anderson J, Kempston J, Boccia A, Petrea C, Babida C, Karmali M, Penner J "Examination of human stomach biopsies, saliva and dental plaque for Campylobacter pylori" J Clin Microbiol, 1989; 27:1397-1398. https://doi.org/10.1128/jcm.27.6.1397-1398.1989

13. Seck A, Burucoa C, Dia D, Mbengue M , Onambele M, Josette Raymond J et Breurec S "Primary antibiotic resistance and associated mechanisms in Helicobacter pylori isolates from Senegalese patients" Ann Clin Microbiol Antimicrobial, 2013; 12 (3): $1-5$.

https://doi.org/10.1186/1476-0711-12-3

14. Kalach N, "Helicobacter pylori primary resistant strains over 11 years in French children" Diagn Microbiol Infect Dis, 2007; 59(2):217-222. PMID: 17662555 https://doi.org/10.1016/j.diagmicrobio.2007.05.003

15. Ben Mansour K, Burucoa C, Zribi M, Masmoudi A, Karoui S, Kallel L, Chouaib S, Matri S, Fekih M, Zarrouk S, Labbene M, Boubaker J Cheikh I, Ben Hriz M, Siala N, Ayadi A, Filali A, Ben Mami N, Najjar T, Maherzi A, Sfar MT, Fendri C "Primary resistance to clarithromycin, metronidazole and amoxicillin of Helicobacter pylori isolated from Tunisian patients with peptic ulcers and gastritis: a prospective multicentre study" Ann Clin Microbiol Antimicrob, 2010; 9(22):1-8. http://www.annclinmicrob.com/content/9/1/22 https://doi.org/10.1186/1476-0711-9-22
16. De Francesco, Giorgio1 F, Hassan C, Manes G, Vannella L, Panella C, Ierardi E, Zullo A "Worldwide H. pylori antibiotic resistance: a systematic review" J Gastrointestin Liver Dis, 2010; 19(4):409414.

17. Naïma RA « Prévalence de l'infection à Helicobacter pylori et typage moléculaire des souches isolées à Alger » [thèse : microbiologie Générale] Alger : Université Ferhat Abbas Sétif. 2018 en Algerie:181p.

18. Atav1 R, Singh D, Rathore P, Jain NP and Goswami RB « Formulation and evaluation of floating pellets of amoxicillin trihydrate for eradication of H. Pylori » WJPR, 2021; 10(9):10241047.

19. Dia D, Moussa GM, Abdoulaye S, Marie-Louise B "Helicobacter pylori and gastroduodenal lesions in Dakar (Senegal)" Méd trop, 2010; 70 (4):367-370. PMID: 22368935

20. Tajeldin MA, Abdelaziem AA « Sero-prevalence and factors associated with Helicobacter pylori infection in Eastern Sudan" Asian Pacific Journal of Tropical Disease, 2014; 4(2): 115-119. https://doi.org/10.1016/S2222-1808(14)60326-1

21. Firmin AA, Dominique NN, Kathleen NB. "Epidemiology of infection Helicobacter pylori in Yaoundé: specificity of the African enigma" Pan African Medical Journal, 2013; 16(115):1-6. https://doi.org/10.11604/pamj.2013.16.115.3007

22. Bossali F, Deby G, Ahoui-Apendi C R, Ndolo D, Ndziessi G, AtipoIbara B I, Ibara J R « Etude de la prise en charge de l'infection à Helicobacter Pylori dans les villes de Pointe-Noire et de Brazzaville en 2015 » Ann. Univ. Mar. Ngouabi, 2017; 17(1):1-9. https://doi.org/10.1007/s12157-015-0623-7

23. Ahmad KB, Ali BU, Musa MB "Prevalence and risk factors for helicobacter pylori infection in gastroduodenal diseases in Kano Nigeria" Asrjets Journal, 2018; 17(1):41-46. https://doi.org/10.4103/ajmhs.ajmhs_36_17

24. Traore $\mathrm{H}$ « Séroprévalence de l'infection à Helicobacter pylori à l'hôpital de SIKASSO » [Thèse : pharmacie] Bamako : Université des sciences, des techniques et de technologies de Bamako, 2020 : 71p.

25. HAS (Haute Autorité de Santé) « Conseil National Professionnel d'Hépato Gastroentérologie. Infection par Helicobacter pylori chez l'adulte » www.has-sante.fr . 2019 mars. Consulté le 10-032021.

26. Joutei HAH, Abderraouf H, Taoufik F,Naima R « Helicobacter pylori infection in 755 patients with digestive complaints » Pasteur Institute, Morocco, 1998-2007, 2010;16 (7):778-782. https://doi.org/10.26719/2010.16.7.778

27. Amel E, Hakima B, Ismail $\mathrm{R}$ « Aspects épidémiologiques et cliniques de l'infection à Helicobacter pylori à travers une étude marocaine » Hegel, 2013; 3(3) :164-168. https://doi.org/10.4267/2042/51450

28. Ngoyi ENO , Ibara BIA, Moyen R, Apendi PCA , Ibara JR, Obengui 0 , Ibara RBO , Nguimbi E, Niama RF, Ouamba JM , Yala F, Abena AA, Vadivelu J, Lee Goh K, Menard A, Benejat L, Sifre E, Lehours P , Megraud F « Molecular Detection of Helicobacter pylori and its Antimicrobial Resistance in Brazzaville, Congo. Helicobacter » Epub, 2015; 20(4):316-320. https://doi.org/10.1111/hel.12204

29. Kimang AN, Revathi G, Kariuki S, Sayed S, Devani S "Helicobacter pylori: prevalence and antibiotic susceptibility among Kenyans" S Afr Med J, 2010;100(1):53-57.

30. Tanih NF, and Ndip RN "Molecular detection of antibiotic resistance in SouthAfrican isolates of Helicobacter pylori" Gastroenterol Res Pract, 2013; 25:945-947. https://doi.org/10.1155/2013/259457

31. Raymond J, Lamarque D, Kalach N, Chaussade S, Burucoa C "High level of antimicrobial resistance in French Helicobacter pylori isolates. Helicobacter" PMID: 20302586, 2010; 15 (1):2127. https://doi.org/10.1111/j.1523-5378.2009.00737.x

32. Djennane-Hadibi F, Bachtarzi M, Layaida K, Arous NA, Nakmouche M, Saadi B, Tazir M, Ramdani-Bouguessa N and Burucoa C "High-Level Primary Clarithromycin Resistance of Helicobacter pylori in Algiers, Algeria: A Prospective Multicenter Molecular Study" Microb Drug Resist, 2016; 22(3):223-226. https://doi.org/10.1089/mdr.2015.0209

33. Fabre $\mathrm{A}$ « Analyse du génome de Campylobacter : une alternative aux antibiogrammes classiques ? » CNRCH, 2016: 135p 